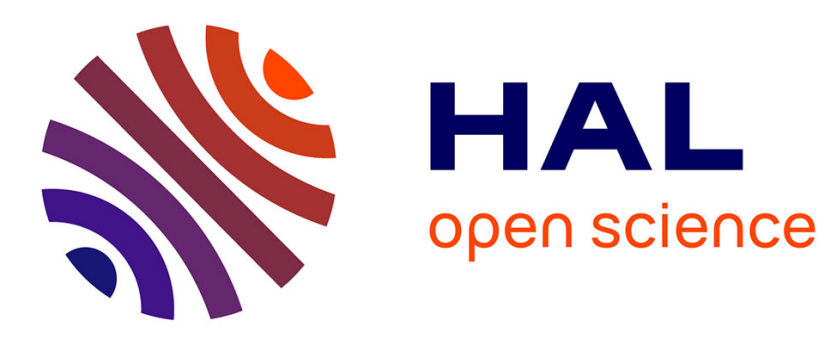

\title{
Efficient simulation of hydraulic fractured wells in unconventional reservoirs
}

Didier Yu Ding, Y. S. Wu, L Jeannin

\section{To cite this version:}

Didier Yu Ding, Y. S. Wu, L Jeannin. Efficient simulation of hydraulic fractured wells in unconventional reservoirs. Journal of Petroleum Science and Engineering, 2014, 122, pp.631 - 642. 10.1016/j.petrol.2014.09.005 . hal-01100260

\section{HAL Id: hal-01100260 \\ https://hal.science/hal-01100260}

Submitted on 6 Jan 2015

HAL is a multi-disciplinary open access archive for the deposit and dissemination of scientific research documents, whether they are published or not. The documents may come from teaching and research institutions in France or abroad, or from public or private research centers.
L'archive ouverte pluridisciplinaire HAL, est destinée au dépôt et à la diffusion de documents scientifiques de niveau recherche, publiés ou non, émanant des établissements d'enseignement et de recherche français ou étrangers, des laboratoires publics ou privés. 


\title{
Efficient simulation of hydraulic fractured wells in unconventional reservoirs
}

\author{
D.Y. Ding ${ }^{a(*)}$, Y.S. Wu ${ }^{\mathrm{b}}$, L. Jeannin ${ }^{\mathrm{c}}$ \\ ${ }^{a}$ IFP Energies nouvelles, 1-4, Avenue Bois-Préau, 92852, Rueil Malmaison, France \\ ${ }^{\mathrm{b}}$ Colorado School of Mines, Golden, Colorado, 80401, USA \\ ${ }^{c}$ GDF SUEZ, 92930, Paris La Defense, France
}

* Corresponding author: didier-yu.ding@ifpen.fr, +33 147526336

\begin{abstract}
Reservoir simulators remain essential tools for improved reservoir management in order to optimize hydraulic fracturing design in unconventional low permeability reservoirs. However, the commonly-used simulator requires too much computational efforts for the description of local phenomena in the vicinity of the hydraulic fractures, and is practically infeasible for field applications, due to large number of gridblocks involved in a full-field simulation with many multifractured complex wells. Therefore, coarse grid simulations have been widely used, but the techniques for the coarse grid simulation of fractured wells need to be improved.
\end{abstract}

In this paper, we present efficient numerical methods to handle both long-term well performance and transient behaviour simulations for hydraulic fractured wells in unconventional reservoirs with a coarse grid. To simulate correctly the long-term behavior, transimissibilities around the fracture and the connection factor between a fractured block and the fracture are computed, based on a (pseudo)-steady-state near-fracture solution. This approach provides not only 
an accurate long-term well production calculation, but also a correct pressure distribution in the near-fracture region. In unconventional reservoirs, the transient effects cannot be ignored, due to the very low reservoir permeability and near-well/near-fracture physical processes such as fracturing fluid induced formation damage. In order to handle the transient effect, the coupled modeling technique is used, and its efficiency is demonstrated with a tight-gas reservoir.

\section{Keywords}

Unconventional reservoir; Hydraulic fractured well; Reservoir simulation; Well model; Fractured well modelling; Coupled modelling

\section{Introduction}

With the increasing demand of hydrocarbon facing current energy shortage, the unconventional resources, such as tight gas and shale gas plays, are becoming more and more important. Significant progress has been made in the past decade for economic development of unconventional petroleum resources. Economic production from unconventional tight and shale gas reservoirs depends upon artificial well stimulation like hydraulic fracturing. Now, reservoir modeling and simulation become increasingly important in order to optimize and improve reservoir management of a tight or shale field by designing fracture length and spacing, and well spacing or infill well location or trajectory, etc.

From a numerical modeling point of view, a single hydraulic fracture can be handled for research purpose using a very refined grid for flow simulation. However, unconventional reservoir developments include many wells with multi-hydraulic fractures. These fractures are long with a length of several hundred meters and narrow with a width of only several millimeters. Besides, 
fracturing in unconventional reservoirs induces usually a complex fracture network by reactivating reservoir natural fractures (see, for example, Delorme et al., 2013; Norbeck et al., 2014). A fine grid numerical model to simulate these field cases requires too much CPU time and it is generally impractical or even impossible to perform fine grid simulations in field applications. So, there is a need to model hydraulically fractured reservoirs with coarse gridblocks.

To simulate hydraulic fractures with a reservoir simulator, some authors suggested using an equivalent wellbore radius or a negative skin factor with a coarse grid (see, for example, Lefevre et al., 1993). But this approach does not produce "elliptical shape" pressure distribution around the fracture and can generate a negative well connection factor for the reservoir simulator. Elahmady and Wattenbarger (2006) proposed to use pseudo-permeabilities to simulate flow perpendicular and along the fracture directions. Zhou and King (2011) used an upscaling method to handle fractured wells in heterogeneous media. Many papers can be found in the literature to discuss the simulation of fractured wells with coarse grids and to propose some practical solutions (see, for example, Sadrpanah, 2006; Gataullin Timur, 2008; Abacioglu et al., 2009; Burgoyne and Little, 2012).

The problem of well modeling has been discussed for a long time. Peaceman's model (Peaceman, 1978; Peaceman, 1983; Peaceman, 1993) has been widely used for reservoir simulations. But that model has its limitations and cannot be used for the fractured well simulation. To improve the well modeling, Ding et al. (1995; 1996; and 2001) proposed to modify the near-well numerical scheme, based on a steady-state or a pseudo-steady-state flow regime, to adapt the singular flow behavior in the near-well region with coarse grid simulations. This concept was also extended for the modeling of fractured wells by Ding and Chaput (1999).

For unconventional reservoir simulations, it is essential to model correctly long conductive fractures such as hydraulic fractures. Li and Lee (2008) proposed to use a transport index (fracture 
connection index) between a matrix block and the fracture to handle embedded discrete fractures. They assumed that the pressure varies linearly in the normal direction to each fracture and they computed an average distance between a fractured block and the fracture for the transport index calculation. The same formula was used by Hajibeygi et al. (2011) in hierarchical fracture model for conductive fracture modeling and by Moinfar et al. (2013) for the simulation of hydraulically fractured unconventional reservoirs. In unconventional reservoir simulations, even with the presence of complex fracture networks, it is common to simulate large hydraulic fractures explicitly using a discrete fracture approach and homogenize short/diffused fractures for a single or dual continuum (see, for example, Moinfar et al., 2013; Wu et al., 2013). The flow transfer between a grid block and a hydraulic fracture as well as between grid blocks near a large fracture needs to be simulated with precisions. However, assuming linear pressure variation is not very accurate near the fracture extremities and in the zone where several fractures are intersected, especially on large gridblocks. In this paper, we propose to compute the fracture connection index (FCI) based on steady-state or pseudo steady-state pressure solution with integral representation. Our approach can handle complex cases like flow modeling near fracture extremities, and it can also be extended to compute flow transports between grid blocks near a fracture. Examples are presented to handle hydraulically fractured wells in unconventional reservoirs. Note that some formation damage issues can also be handled through the modification of connection factors (or skin) between a fractured block and the fracture.

Another issue related to the fractured well simulation in unconventional reservoirs is the modeling of transient flow behavior. In a conventional reservoir, the transient period is generally very short, and a pseudo-steady-state flow regime is quickly reached in the near-well/near-fracture region. The transient behavior can generally be neglected in conventional reservoir simulations, except for transient well testing. However, the transient behavior cannot be ignored in low permeability unconventional tight and shale gas reservoirs. Artus and Fructus (2012) used very fine 
meshes to simulate transient behavior in shale-gas reservoirs and they showed the necessary to improve transmissibility calculation even for very fine mesh connections around the fractures, especially near the fracture extremities.

Coarse gridblock is generally not adapted to the modeling of transient behavior (the size of the gridblock is too large compared to variation length of physical variables such as pressure, saturation) and the description of near-well/near-fracture physical processes. To simulate the transient behavior, Blanc et al. (1999) proposed a transient well index, based on an analytical solution, to handle well testing problem for vertical wells. Al-Mohammadi et al. (2007) and Aguilar et al. (2007) used time-dependent well index to simulate horizontal and multilateral wells. Archer (2010) also shows the necessary of transient well index for the coarse grid simulation. The transient effect becomes particularly important for fractured wells in the unconventional reservoir due to long fracture length and low reservoir permeability or long transient flow period (Medeiros et al. 2007; Ibrahim, 2013).

Transient effects associated with the near-well/near-fracture physical process are generally more complex. For a fractured well in an unconventional reservoir, the typical physical process is the fracturing fluid induced formation damage and cleanup (Bennion et al. 2000; Friedel, 2004; Ding and Regard, 2005; Cheng, 2012; Agrawal and Sharma, 2013; Bertoncello et al., 2014) or possible non-Darcy flow inside the fracture towards the well (Wu, 2002). All these studies require the use of very fine gridblocks around the fractures, and it is difficult to investigate well production behavior in a full-field context. Besides, a full-field reservoir simulator might not have all the options to simulate detailed near-well/near-fracture physical processes. In order to take into account the transient flow and near-well/near-fracture physics on one side and long-term production behavior on the other side, we propose to use the coupled modeling technique (Ding et al., 2010; 2012). A coarse grid model is used for the long-term production simulation, and a detailed near- 
well/near-fracture model is used to simulate near-well/near-fracture physics. These two models are linked through a time-dependent numerical productivity index and/or fracture connection index.

In this paper, we will present first the well model, based on a steady-state (or pseudo-steadystate) flow regime, for the simulation of fractured wells, which is suitable for long-term well productivity calculation. Then the transient behavior related to coarse gridblock size and nearwell/near-fracture physical processes is modeled through the technique of coupled modeling. Examples are presented and show that these two combined approaches are well suited for the simulation of fractured wells in unconventional reservoirs.

\section{Coarse Grid Simulation of Fractured Wells}

\subsection{Problems of Previous Fractured Well Modeling}

Peaceman's well model (Peaceman 1978; 1983; 1993) has been widely used in flow simulators. To compute the wellbore pressure (with a constrained well flow rate) or the well flow rate (with an imposed bottom-hole pressure), Peaceman (1978) introduced a numerical productivity index (PI) on a wellblock $W_{0}$ to relate the wellbore pressure $P_{w 0}$, the well flow rate $Q_{0}$ to the simulated wellblock pressure $P_{0}$, by:

$$
Q_{0}=P I\left(P_{0}-P_{w 0}\right)
$$

with the numerical PI given by:

$$
P I=\frac{C}{\ln \left(\frac{r_{0}}{r_{w}}\right)+S}
$$

where $C$ is a positive constant, depending on the well length and the permeability on the wellblock, $S$ is the skin factor, $r_{w}$ is the wellbore radius, and $r_{0}$ is the equivalent wellblock radius, which 
depends on the wellblock size and the well trajectory on the wellblock. For example, for a fully penetrating vertical well in a 2D square gridblock, the equivalent wellblock radius is given by:

$$
r_{0}=0.2 \Delta x
$$

with $\Delta x$ the gridblock size.

It is not difficult to find that the Peaceman's formula is not suitable for the fractured well modeling. One solution for the simulation of fractured wells is using the concept of an equivalent wellbore radius, which equals $1 / 2$ of the fracture half length, or a negative skin factor. However, several problems arise with the equivalent wellbore radius or a negative skin factor:

1. The wellblock cannot be too small. If the wellblock size $\Delta x$ is smaller than 2.5 times of the fracture half length, the numerical PI becomes a negative value. For example, for a fracture with a half length of $100 \mathrm{~m}$, the wellblock size cannot be smaller than $250 \mathrm{~m}$. In term of skin, it cannot be too small so that $\ln \left(\frac{r_{0}}{r_{w}}\right)+S$ is negative. This constraint limits many applications.

2. The elliptic pressure distribution in the vicinity of a fractured well is modeled by a radial one.

3. The simulated result is not accurate before a pseudo steady-state regime is reached around the whole fracture. The transient period is as long as the fracture length increasing.

4. The above equivalent wellbore radius is based on the infinite conductivity assumption. The flow inside the fracture is not considered.

5. This model is not valid in heterogeneous media.

\subsection{Improved Well Modeling}


To improve the well modeling, Ding et al. (1995; 1996; and 2001) proposed to ameliorate the numerical scheme for near-well flow calculations. An accurate near-well flow approximation improves automatically the numerical PI formulation. In general, if a near-well steady-state or pseudo-steady-state solution is known, we can determine a suitable numerical scheme by identification for correct flow calculations. Considering a simplified two-point flux approximation scheme:

$$
F_{i j}=T_{i j}\left(P_{j}-P_{i}\right)
$$

where $P_{i}$ and $P_{j}$ are pressures on the block $i$ and $j, F_{i j}$ is the flux term across the edge $\Gamma_{i j}$ (Figure 1), the transmissibility term $T_{i j}$ can be determined with a (pseudo) steady-state flow solution by:

$$
T_{i j}=\frac{F_{i j}^{s}}{\left(P_{j}^{s}-P_{i}^{s}\right)}
$$

where $P_{i}^{s}$ and $P_{j}^{s}$ are the (pseudo) steady-state pressure on the blocks $i$ and $j, F_{i j}^{s}$ is the (pseudo) steady-state flux across the edge $\Gamma_{i j}$. The pressure variation in the vicinity of the well is very big due to the singular near-well flow behavior. On the wellblock, we can define the wellblock pressure as a volumetric average pressure or a pressure at a distance $r_{0}$ from the well. Once the wellblock pressure is well defined, we can naturally determine the numerical PI for Eq.(1) by:

$$
P I=\frac{Q_{0}^{S}}{\left(P_{0}^{S}-P_{w}^{S}\right)}
$$

where $Q_{0}^{S}$ is the well flow rate on the wellblock $W_{0}$ under a (pseudo) steady-state regime, $P_{0}^{s}$ and $P_{w}^{s}$ are respectively the wellblock pressure and the wellbore pressure under the (pseudo) steadystate regime. So, with this approach, the near-well flow can be correctly handled and the numerical PI can also be easily determined. 


\subsection{Imroved Fractured Well Modeling}

For a fractured well, two problems should be considered in the flow modeling: flow from the reservoir to the fracture, and flow from the fracture to the well. The modeling of flow from the reservoir to the fracture is the most important one. Inspired by the well modeling with a numerical PI, we introduce a fracture connection index (FCI), which relates the pressure on a fracture block $P_{0}$, the fracture pressure $P_{f 0}$ on the same block and the flow rate entering to the fracture $Q_{f 0}$ by:

$$
Q_{f 0}=F C I\left(P_{0}-P_{f 0}\right)
$$

Considering a fully penetrated fracture (a 2D problem), a steady-state flow equation in the vicinity of the fracture in a homogeneous medium is given by:

$$
\frac{\partial^{2} P^{s}}{\partial x_{1}^{2}}+\frac{\partial^{2} P^{s}}{\partial x_{2}^{2}}=0
$$

with some boundary conditions at the fracture boundary $\Gamma_{f}$ (Figure 2), for example,

$$
P^{s}(x)=P_{f} \quad x=\left(x_{1}, x_{2}\right) \in \Gamma_{f}
$$

for the Dirichlet condition, or

$$
\frac{\partial P^{s}}{\partial n}(x)=Q_{f} \quad x=\left(x_{1}, x_{2}\right) \in \Gamma_{f}
$$

for the Neumann condition.

Appendix presents a boundary integral method (sometimes also called semi-analytical method) to solve this steady-state problem. In particular, an analytical solution can be obtained with a constant potential condition (equivalent to the well-known uniform flux condition for the fractures). Once the steady-state solution is obtained, we can determine the transmissibility around the fracture by Eq.(5) and the fracture connection index (FCI) by:

$$
F C I=\frac{Q_{f 0}^{s}}{\left(P_{0}^{s}-P_{f 0}^{s}\right)}
$$


The pressure distribution, under a (pseudo) steady-state flow, depends mainly on the position of the fracture, and much less on the fracture conductivity. The transmissibilities and FCIs, obtained with a constant potential steady-state solution, can adequately be applied to the simulation of fractured wells with a wide range of conductivity values as shown in the examples hereafter.

It is generally recognized the importance of accurate modeling of flow transport between matrix and conductive fractures. Li and Lee (2008) assumed that the pressure varies linearly around the fracture and computed an average distance of a fractured block to the fracture for the matrixfracture transfer calculation. The same approach are recently applied to flow simulation in unconventional reservoirs (Moinfar et al., 2013; Norbeck et al., 2014) by considering the presence of main hydraulic fractures and a complex fracture network. However, using linear pressure assumption is not suitable for flow modeling near fracture extremities and in the zone of fracture intersections, especially for large gridblocks. Artus and Fructus (2012) illustrated the necessary of considering particular matrix-fracture flow near hydraulic fracture extremities. The formula proposed in this paper improves the matrix-fracture interaction for long conductive fractures, and examples below shows the accuracy of our approach.

In heterogeneous media, no analytical or semi-analytical (pseudo) steady-state solution is available. However, we can use a technique similar to the near-well upscaling procedure (Ding, 1995; Mascarenhas and Durlofsky, 2000) by solving a steady-state problem with a fine grid numerical simulation. The obtained fine grid solution is then used to compute the transmissibility around the fracture and fracture connection index (FCI) from Eqs.(5) and (11).

With this improved model for the fractured well modeling, the problems mentioned above are solved, in particular, 
- The concept of an equivalent wellbore radius is not used, so there is no limitation on the gridblock size.

- The near-fracture pressure and flow distribution can be correctly handled, as the numerical scheme in the near-fracture region is modified to adapt the near-fracture flow behavior.

- The transient behavior due to long fracture length can be partly reduced, because a pseudosteady-state regime can be quickly attained in a scale between two neighboring gridblocks, much faster than in the whole fracture region.

- This approach is not limited to an infinite conductivity fracture. Besides, this approach can be applied to a wide range of fracture conductivities, even if the flow regime is determined with a particular boundary condition (constant potential or other boundary conditions).

- This concept can be extended to heterogeneous media.

Moreover, this approach can also be used for flow simulation with general discrete fracture network.

Flow inside the fracture has also to be considered, especially, for low conductivity fractures. In general, the simulation uses Darcy's law with a given fracture permeability to simulate flows inside the fracture. In the fracture plane, the well is considered as a sink/source at the intersection point between a horizontal well and the created fracture. So, the technique of well model (Peaceman, 1983; Ding et al. 1995) can be directly applied to handle the radial flow inside the fracture towards a horizontal well. However, if a 1D grid is used inside the fracture (as shown in the examples hereafter), precaution should be taken, because a 1D grid cannot simulate correctly the radial flow behavior towards a horizontal well. Nevertheless, this has almost no impact on high conductivity fractured wells, as the pressure drop is very low along the fracture due to the high fracture conductivity. But errors can be significant in low conductivity fractures. One solution, as illustrated in the example below, is to introduce a skin factor or modify numerical PI for the connection between the wellblock (block containing the intersection of the well and the fracture inside the fracture plane) and the well to mimic a 2D radial flow in the fracture plane. 


\section{Remark:}

For the fractured well modeling, we use numerical PI to represent the connection between the well and the fracture, and FCI to represent the connection between the fracture and the reservoir.

\subsection{Incorporation of Near-Well/Near-Fracture Physics and Coupled Modeling}

Many physical processes may change near-well/near-fracture flow and formation properties. Concerning the fractured well, formation damage issue is greatly discussed (Bennion et al. 2000; Friedel, 2004; Ding and Regard, 2005; Agrawal and Sharma, 2013; Bertoncello et al., 2014). In general, formation damage in fractured wells falls into two categories: damage inside the fracture and damage inside the formation. The damage inside the fracture can be caused by proppant crushing, proppant embedment, fracture plugging with chemicals and polymer residues. The damage inside the reservoir is classified by mechanical damage and hydraulic damage. The mechanical damage, which is generally characterized by a reduction of absolute permeability, includes polymer solids deposition near the fracture face, clay swelling, broken gel/fine migration, etc. The hydraulic damage occurs from the increase in water saturation caused by the fracturing fluid invasion into the porous media. It includes the hysteresis of relative permeability and high capillary pressure, water blocking, etc. The hydraulic damage reduces the gas flow in the zone, where the fractured fluids are invaded.

The formation damage can be characterized with skin factors. For a fractured well, if the formation damage is inside the reservoir, a skin is added to FCI term for the connection between the reservoir and the fracture. If the formation damage is inside the fracture, a skin is added to numerical PI term for the connection between the fracture and the intersected well. In Ding and Renard (2005), they presented a procedure for the determination of long-term numerical PIs for 
formation damage around a well. The similar procedure can be applied to determine FCIs for the formation damage near fracture faces. According to the physical problem, we will choose suitable indices (numerical PI and/or FCI) to integrate the damage effect.

Some physical processes alter progressively the near-fracture formation, and we cannot use constant skin factors (associated with numerical PI and/or FCI) to mimic this process. One solution is to use variable numerical PI and/or FCI through a coupled modeling (Ding et al. 2010). The coupled modeling is initially developed to update numerical PIs for a full-field coarse grid simulation. This technique is also suitable for updating FCIs for coarse grid fractured well simulations. The coupled modeling is particularly useful in the two following situations:

1. Large gridblock size and low permeability.

2. Near-well/near-fracture damage process acts in a long period.

In coupled modeling, data exchanges between the reservoir model and the near-fracture model are performed through updating numerical PIs and/or FCIs for the reservoir model and boundary conditions for the near-fracture model. The updated numerical PIs and/or FCIs correct inaccuracies in the coarse grid simulation. This technique can improve considerably the modeling of transient effect for fractured wells in full-field reservoir simulations.

\section{Numerical examples}

\subsection{Example 1 - Coarse grid simulation of a single fractured well}

In this example, we study how to handle a single fractured horizontal well with a coarse grid, and investigate the impact of different reservoir permeabilities, corresponding to a low permeability 
conventional reservoir, a tight gas reservoir and a shale gas reservoir, on the well performance simulation.

Considering a half-geometry with respect to the fractured well as shown in Figure 3. A fracture with half length of $125 \mathrm{~m}$ and width $0.5 \mathrm{~cm}$ is first simulated with a very fine grid, starting with gridblock size of $0,25 \mathrm{~cm}$ around the fracture (Figure 3a), and the reservoir thickness is discretized by 5 layers with gridblock sizes of $10 \mathrm{~m}$. The horizontal well is drilled in the middle layer. This reservoir zone is also discretized with an uniform 2D coarse grid with block size of $50 \mathrm{~m}$ in $\mathrm{x}$ and $\mathrm{y}$ directions and only 1 layer in z-direction (Figure 3b). For the coarse grid, the fractured well model presented above with a constant potential boundary condition is applied to handle the near-fracture flow by modifying the transmissibilities. It is assumed that only the fracture contributes the production. The reservoir water is immobile with irreducible water saturation of 0.2 . Only gas flow is considered.

First, considering a low permeability "conventional" reservoir with permeability of $2 \mathrm{mD}$. Figure 4 presents a comparison between fine and coarse grid simulations on the gas production for a fracture permeability of 5D, 50D and 5000D (or a dimensionless fracture conductivity $C_{f}=0.1,1$ and 100). The dimensionless fracture conductivity is defined by

$$
C_{f}=\frac{K_{f}}{K_{\text {res }}} \frac{w}{X_{f}}
$$

with $K_{f}$ the fracture permeability, $K_{\text {res }}$ the reservoir permeability, $w$ the fracture width, and $X_{f}$ the fracture half length. The maximum gas production is limited to $10^{6} \mathrm{~m}^{3} /$ day. For the low fracture conductivity case, a significant difference between the coarse and fine grid simulations is observed, while for high fractures conductivities, the presented model is perfectly suitable for the coarse grid simulation. The transient period is less than 1 day due to high reservoir permeability. 
In the coarse grid simulation, the fracture is discretized with a 1D grid. For high fracture conductivity, all gas in the fracture is quickly produced by the well, and the pressure drop near the well (inside the fracture) is small. So, the error on the well modeling between the fracture and the well is not observed. However, for a low conductivity case such as $C_{f}=0.1$, not all gas in fracture are immediately produced by the well, and the pressure drop inside the fracture is important. To correct errors in flow modeling from the fracture to the well, we adapt here a simple approach by introducing a skin factor for the connection between the fracture and the well (or modify the numerical PI). The skin (or modified numerical PI) is obtained using the inversion procedure (Ding and Renard, 2005) by comparing with a pseudo-steady-state solution from a fine grid simulation. The coarse grid simulation results with the inversed skin factor for $C_{f}=0.1$ (fracture permeability 5 D) is also shown in Figure 4a. Very satisfactory result is obtained.

Figure 3 presents also the pressure distribution at 800 days for $C_{f}=100$ with the fine and coarse grid simulations. These two pressure distributions are quite similar. Using the proposed fractured well model can correctly simulate fractured wells with a coarse grid system. The transient effect in a conventional reservoir is very small.

Now consider a tight-gas reservoir with a reservoir permeability of $0.02 \mathrm{mD}$. If we still use a fracture permeability of $5 \mathrm{D}$ and $50 \mathrm{D}$, the dimensionless conductivity becomes 10 and 100, much higher than those in a conventional reservoir. Figure 5 compares the gas production rate with the coarse and fine grid simulations. The coarse grid simulation provides generally accurate long-term production, but it remains inaccurate in early-time period due to large coarse gridblocks and lower reservoir permeability. The transient duration depends on the fracture permeability (or conductivity). In case of high fracture permeability, the transient period may last around 20 days, but the difference between coarse and fine grid simulations is not very large. Figure 6 shows the pressure distribution at 800 days with fine and coarse grid simulations. The pressure distributions around the 
fracture are quite similar. Thus, we can simulate a fractured well in the tight-gas reservoir with a coarse grid with reasonable precisions, especially for long-term well production.

The transient effect seems limited in this example, because we consider only a single-phase Darcy flow. The transient effect can be much more important if other physical processes such as formation damage are considered. Figure 7 shows a fine grid simulation by considering fracturing fluid induced formation damage for the case of $\mathrm{K}_{\mathrm{f}}=5 \mathrm{D}$. It is found that the errors related to the coarse grid simulation are more important, due to the presence of fracturing fluid, and the transient regime lasts longer. In Example 2 below, we will study details of the transient effect related to the fracturing induced formation damage and show how to correctly handle this effect with a coarse grid simulation using the couple modeling technique.

For the shale-gas or ultra-tight reservoir, the tight matrix permeability is extremely low. Let's consider a reservoir matrix permeability of $0.0001 \mathrm{mD}$. In case of a hydraulic fracture permeability of $5 \mathrm{D}$, the dimensionless conductivity is as high as 2000 . Figure 8 a shows the simulation results with the coarse and fine grid systems. As the matrix permeability is ultra-low, a pseudo-steady-state regime cannot be reached before several years. At the beginning, gas production is underestimated with the coarse grid system due to its large gridblock sizes, which cannot simulate correctly the gas flow in the reservoir close to the fracture. This phenomenon lasts for a very long time. Later on, after the gas near the fracture is produced with the fine grid model, the coarse grid model starts to overestimate the gas production, because of the remained gas in the near-fracture coarse blocks. Figure $8 \mathrm{~b}$ and $8 \mathrm{c}$ show the simulation results with a lower fracture conductivity ( $C_{f}=160$ and 16 respectively). For all simulations, the durations of transient period with the coarse grid system are almost the same. Only long-term production is slightly improved with low fracture conductivity. 
The transient period is too long in above simulations, and it is not suggested to use a transient numerical PI or FCI during a very long time period. A slight reduction of fracture block size can significantly decrease the transient time. Figure 9 presents the simulation with one level grid refinement by subdividing a fracture block into two parts: a (fracture) block with a width of 10 $\mathrm{m}$ and a block with a width of $40 \mathrm{~m}$. This subdivision reduces the transient period by almost a factor of 10. The coupled modeling can, therefore, be conveniently applied to simulate the transient effect if necessary.

The production with a fractured well generally follows two steps: flow from matrix to the fracture and then from the fracture to the well. In a shale-gas reservoir, the production is usually limited by the matrix-fracture transfer for the flow from the reservoir to the fracture. Transient effect with a coarse grid is extremely long. It has to be mentioned that the fracture system in a shale gas reservoir is much more complex than a single hydraulic fracture. Co-existence of fracture networks and natural fractures are usually needed to be considered. To simulate fractured wells in a shale-gas reservoir with a coarse grid, it is necessary to use a dual-porosity model and implement the fractured well modeling technique for dual-porosity simulations, which is our ongoing work.

In summary, the modeling technique presented in this paper can improve the simulation efficiency of fractured wells with a coarse grid system. When using a 1D grid in the fracture plane, a skin can be used to correct errors for the flow simulation from the fracture to the well. But this is not necessary if the fracture conductivity is high. For a low permeability "conventional" reservoir, transient effect can generally be neglected. For the tight gas reservoir, handling of transient period with a coarse grid simulation is an issue, especially when considering some damage processes. For the shale gas reservoir, the transient period depends greatly on the fracture block size, and the transient time might be extremely long. We should reasonably reduce the gridblock sizes for the fracture blocks in shale-gas reservoir simulations. 


\subsection{Example 2 - Coarse grid simulation with coupled modeling}

Considering a tight-gas reservoir of $1000 \mathrm{~m} \times 1000 \mathrm{~m} \times 50 \mathrm{~m}$. The reservoir is water undersaturated: the initial reservoir water saturation of 0.2 is smaller than the irreducible water saturation of 0.28 , which will induce water blocking in the fracturing fluid invaded zone. The relative permeability and capillary pressure curves are shown in Figure 10. The average horizontal permeability is $0.02 \mathrm{mD}$ and the vertical and horizontal permeability ratio is 0.5 .

Two wells are drilled in this reservoir: one multi-fractured horizontal well with 3 transverse fractures (W1) and one single-fractured horizontal well (W2). Figure 11a shows the coarse grid model and the location of these two fractured wells. All fracture half lengths are $50 \mathrm{~m}$ and its width is $1 \mathrm{~cm}$. The dimensionless fracture conductivity in the multi-fractured horizontal well (W1) is 2 , and it is 20 in the single-fractured horizontal well (W2). In all the wells, only fractures contribute directly the gas productions. Due to water blocking, the gas relative permeability is reduced from 0.59 to 0.37 in the damaged zone (fracturing fluid invaded area). At the beginning of production, gas is produced together with the injected fracturing fluid, which reduces the gas flow rate in the cleanup period.

For the coarse grid simulation, the reservoir is discretized by 20 gridblocks in $\mathrm{x}$-direction, 20 gridblocks in y-direction and 5 blocks in z-direction with gridblock size of $50 \mathrm{~m} \times 50 \mathrm{~m} \times 10 \mathrm{~m}$ as shown in Figure 11a. Transmissibilities around the fractures are modified by using Eq.(5) and the fracture connection indices FCI are given by Eq.(11) based on a constant potential steady-state flow.

Well W1 is drilled and fractured first. Well W2 is drilled and fractured one month later. A volume of $300 \mathrm{~m}^{3}$ of water-based polymer is injected to create the each fracture, and the wells are shut in for two days before putting into productions. To simulate the fracturing fluid invasion and 
its cleanup, very fine gridblocks (sizes of several centimeters) are required around the fractures to get the reference solution, as the invasion depth is usually of the order of several to several tens centimeters. Figure 12 presents a comparison of gas production between the coarse grid simulation with constant PIs and the reference solution. It is found that the coarse grid model cannot simulate the fracturing fluid invasion and the cleanup, due to large sizes of the fracture blocks. In fact, the initial reservoir saturation of 0.2 is lower than the irreducible water saturation of 0.28 . Because of the large block size, all the injected fracturing fluid is blocked in the coarse gridblock and cannot be reproduced. A big difference is observed in early-time, due to the cleanup process and large gridblock sizes. The transient period lasts for around 200 days for the well W1. Nevertheless, the long-term simulation is quite satisfactorily simulated with the coarse grid. Although some drilling fluid is still trapped inside the reservoir, it has not much impact on long-term well productions, because the flow is linear close to the fracture face and the damage in a small zone near the fracture does not have much impact on the linear flow (perpendicular to the fracture). This example also shows that the fracturing fluid induced formation damage has little impact on long-term gas production, but the cleanup period may last several months. It may also be much longer according to the reservoirs.

To take into account the transient effects, the coupled modeling is used in the early time simulation when the well is fractured and starts the production. Figure 11 also shows the fine grid models and their corresponding zones in the coarse grid. The coupled modeling for these two wells does not start at the same time, and the coupling periods are also different. Figure 13 presents schematically the periods for the coupled modeling. The coarse grid full-field simulation is performed for a total of 800 days. The coupled modeling for well W1 starts with the injection of fracturing fluid at the $1^{\text {st }}$ day. The duration of the coupling modeling is 200 days for this low conductivity multi-fractured well, because the cleanup time is long for a low conductivity fracture. In the same time, well $\mathrm{W} 2$ is fractured at the $31^{\text {th }}$ day. So the coupled modeling for well W2 is 
started at the $31^{\text {th }}$ day, and ended at the $61^{\text {th }}$ day for a period of 30 days for this high conductivity fractured well. Table 1 presents the time steps for the data exchanges in the coupled modeling of these two wells. In this coupled modeling, we update the numerical PIs for the connections between the fractures and the well. Figure 14 presents the simulation results of the coupled modeling. These results are very close to the reference solutions, which are obtained using local grid refinement with very fine gridblocks around the fractures.

This example shows that the proposed model, obtained by modifying the near-fracture transmissibility and the fracture connection factor FCI to adapt near-fracture flow behavior, gives very satisfactory solution for long-term well production. However, the differences between using the constant numerical PI and transient PI (or the reference model) are significant during the early time. To take into account near-fracture damage process, it is essential to use a coupled modeling, where the transient affects, related to the fracturing fluid induced formation damage and gridblock sizes, can be correctly handled through time-dependent PIs. The transient effect is small for high conductivity fractures, while it is large for low conductivity fractures. This example shows also the importance of a high fracture conductivity, since the single fractured well W2 with a conductivity of 20 can produce almost the same volume as the 3 fractured well W1 with a conductivity of 2 .

\section{Discussions and Conclusions}

This paper studies the techniques for fractured well simulations in unconventional reservoirs with a coarse grid. A fractured well model, based on near-fracture transmissibilities and fracture connection indices determined from a steady-state flow regime, is proposed. This model is well 
suited for the simulation of long-term well production. If the near-well/near-fracture formation damage processes can be neglected, this model is suitable for the simulation of fractured wells in low permeability "conventional" reservoirs as well as unconventional tight-gas reservoirs. For shale-gas reservoirs, the transient period may be very long with a large coarse grid. A reasonable block size for fracture blocks (of the order of several meters) is required.

In homogeneous media, an analytical steady-state solution can be obtained using constant potential condition (equivalent to the uniform flux condition), and the fractured well modeling based on that solution is accurate enough for a wide range of fracture conductivity values. In heterogeneous media, the upscaling procedure, based on a fine grid simulation, can be used. Satisfactory simulation results make us confidence to generalize this approach to more complex discrete fracture networks.

Accurate simulation of flow inside the fracture plane is also required for low conductivity fractures, especially if a fracture is simulated with a 1D grid. One practical solution is using a skin factor or modifying the numerical PI with an inversion procedure.

Transient flow may occur during early-time due to large grdiblcok, low permeability and some near-well/near-fracture physical processes. The transient period may be very long and important according to the reservoir and damage process. To handle the transient flow simulation with a coarse grid system, time-dependent numerical PIs and/or FCIs are necessary. The coupled modeling is a useful technique to provide time-dependent numerical PI for coarse grid simulations, even if the coarse grid model does not dispose the option to simulate the near-well/near-fracture physical processes. 


\section{Nomenclature:}

\begin{tabular}{|c|c|}
\hline$C$ & a constant \\
\hline$C_{f}$ & dimensionless fracture conductivity \\
\hline$F$ & flow across a block edge \\
\hline$F C I$ & fracture connection index \\
\hline$K$ & permeability \\
\hline$P$ & pressure \\
\hline$P_{0}$ & pressure at a wellblock or a fracture block \\
\hline$Q$ & well flow rate \\
\hline$r_{0}$ & equivalent wellblock radius \\
\hline$r_{w}$ & wellbore radius \\
\hline$P I$ & (numerical) productivity index \\
\hline$S$ & skin \\
\hline$T$ & transmissibility \\
\hline$x$ & a 2D point with $x=\left(x_{1}, x_{2}\right)$ \\
\hline$x_{1}$ & coordinates \\
\hline$x_{2}$ & coordinates \\
\hline$X_{f}$ & fracture half length \\
\hline$y$ & a $2 \mathrm{D}$ point with $y=\left(y_{1}, y_{2}\right)$ \\
\hline$y_{1}$ & coordinates \\
\hline$y_{2}$ & coordinates \\
\hline$w$ & fracture width \\
\hline$W_{0}$ & wellblock \\
\hline$\varphi$ & potential \\
\hline$\Gamma$ & fracture boundary \\
\hline
\end{tabular}




$$
\begin{array}{ll}
\Gamma^{+} & \text {fracture boundary outside the fracture } \\
\Gamma^{+} & \text {fracture boundary inside the fracture } \\
\Delta x & \text { gridblock size }
\end{array}
$$

\section{Subscripts}

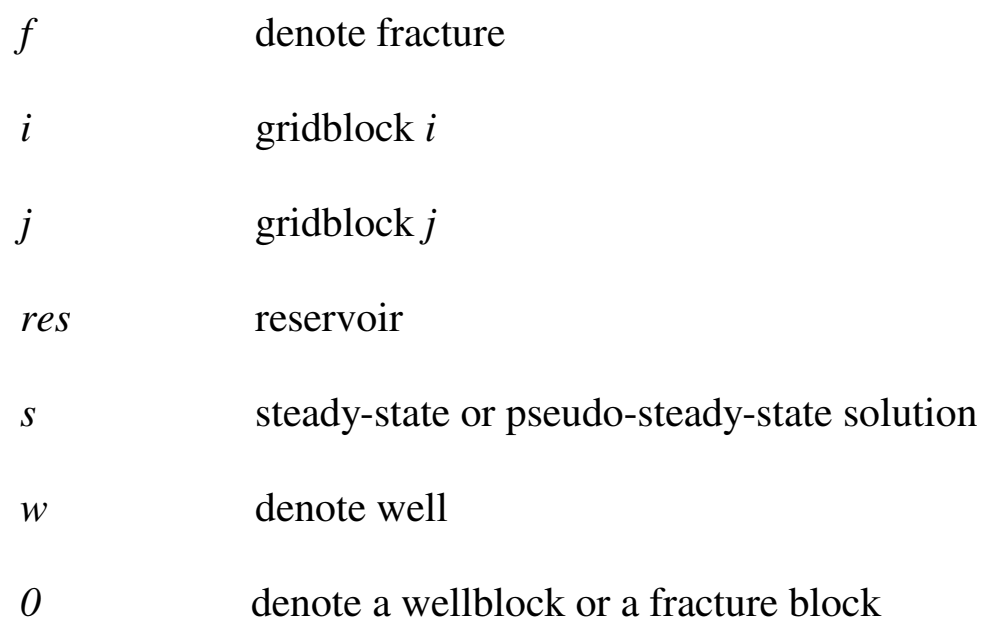

\section{References:}

Abacioglu, Y., Sebastian, H.M. and Oluwa, J.B. (2009) "Advancing Reservoir Simulation Capabilities for Tight Gas Reservoirs" SPE 122793 presented at the 2009 SPE Rocky Mountain Petroleum Conf., Denver, CO, USA, 14-16 April.

Agrawal, S. and Sharma, M. (2013) "Liquid Loading Within hydraulic Fractures and its Impact on Unconventional Reservoir Productivity", SPE 168781 /URTeC 1580636, Unconventional Resources Technology Conference held in Denver, Colorado, USA, 12-14 August.

Aguilar, C., Ozkan, E., Kazemi, H., Al-Kobaisi, M. and Ramirez, B. (2007) "Transient Behavior of Multilateral Wells in Numerical Models: A Hybrid Analytical-Numerical Approach”, SPE 104581 presented at the $15^{\text {th }}$ SPE Middle East Oil \& Gas Show and Conf., Bahrain, 11-14 March. 
Al-Mohannadi, N., Ozkan, E. and Kazemi, H. (2007) "Grid-System Requirements in Numerical Modeling of Pressure-Transient Tests in Horizontal Wells" SPE Reservoir Evaluation \& Engineering, April, pp122-131.

Archer, R.A. (2010) “Transient Well Indices: A Link Between Analytical Solution Accuracy and Coarse Grid Efficiency”, SPE 134832 presented at the SPE ATC\&E, Florence, Italy, 19-22 Sept. Artus, V. and Fructus, D. (2012) "Transmissibility Corrections and Grid Control for Shale Gas Numerical Production Forecasts" Oil \& Gas Science and Technology, Vol.67, No.5, pp805-821.

Blanc, G., Ding, D.Y., Ene, I-A. and Estebenet, T. (1999) "Transient Productivity Index for Numerical Well Test Simulations" Reservoir Characterization, AAPG Memoir 71, Ed. Schatzinger and Jordan, 1999, pp163-174.

Bennion, D.B., Thomas, F.B. and Ma, T. (2000) "Recent Advances in Laboratory Test Protocole to Evaluate Optimum Drilling, Completion and Stimulation Practices for Low Permeability Gas Reservoirs" paper SPE 60324, presented at the SPE Rocky Mountain Regional/Low-Permeability Reservoirs Symposium and Exhibition, Denver, CO, March 12-15.

Bertoncello, A., Wallace, J., Blytin, C. and Kabir, C.S. (2014) "Imbibition and water blockage in unconventional reservoirs: well management implications during flowback and early production", SPE 167698, presented at the Euroupean Unconventional Resources Conf., Austria, 25-27 February.

Burgoyne, M.W. and Little, A.L. (2012) "From High Perm Oil to Tight Gas - A Practical Approach to Model Hydraulically Fractured Well Performance in Coarse Grid Reservoir Simulators”, SPE 156610 presented at the SPE Asia Pacific Oil and Gas Conf. \& Exhi., Perth, Australia, 22-24 Oct. Cheng, Y. (2012) "Impact of Water Dynamics in Fractures on the Performance of Hydraulically Fractured Wells in Gas-Shale Reservoirs", Journal of Canadian Petroleum Tech., March. Pp143151. 
Delorme, M., Daniel, J.M., Kada-Kloucha, C., Khvoenkova, N., Schueller, S., and Souque, C. (2013) "An Efficient Model to Simulate Reservoir Stimulation and Induced Microseismic Events on 3D Discrete Fracture Network for Unconventional Reservoirs", Paper SPE 168726 presented at the Unconventional Resources Technology Conference, Denver, CO, USA, 12-14 August.

Ding, Y., Renard, G., and Weill, L. (1995) "Representation of Wells in Numerical Reservoir Simulation" SPE 29123 presented at the $13^{\text {th }}$ Reservoir Simulation Symposium, San Antonio, USA, 12-15 Feb.

Ding, Y. (1995) "Scaling-up in the vicinity of wells in a heterogeneous field”, Paper SPE 29137 presented at the 13th Symposium on Reservoir Simulation, San Antonio, USA, 12-15, Feb.

Ding, Y. (1996) "A Generalized 3D Well Model for Reservoir Simulation" SPE Journal, Dec., pp437-450.

Ding, Y. and Chaput, E. (1999) "Simulation of Hydraulically Fractured Wells" Petro. Geoscience, Vol. 5 Aug., pp265-270.

Ding, D.Y. and Jeannin, L. (2001) "A New Methodology for Singularity Modeling in Flow Simulations in Reservoir Engineering" Comp. Geosciences, Oct., pp93-119.

Ding, D.Y. and Renard, G. (2005) "Evaluation of Horizontal Well Performance after Drilling Induced Formation Damage” J. of Energy Resources Technology, Vol. 127, Sept., pp257-263.

Ding, D.Y. (2010) "Modeling Formation Damage for Flow Simulations in Reservoir Scale" SPE Journal, Vol. 15, No. 3.

Ding, D.Y., Langouet, H. and Jeannin, L. (2012) "Simulation of fracturing induced formation damage and gas production from fractured wells in tight gas reservoirs", SPE 153255 presented at the 2012 SPE East Unconventional Gas Conference and Exhibition, Abu Dhabi, 23-25 Jan. 
Elahmady, M. and Wattenberger, R.A. (2006) "Coarse Scale Simulation in Tight Gas Reservoirs", J of Canadian Petroleum Technology, Vol. 45, No. 12, Dec.

Friedel, T. (2004) "Numerical Simulation of Production from Tight-Gas Reservoirs by Advanced Stimulation Technologies", PhD Thesis, Freiberg University.

Gataullin Timur (2008) "Modeling of Hydraulically Fractured Wells in Full Field Reservoir Simulation Model” SPE 117421 presented at the 2008 SPE Russian Oil \& Gas Tech. Conf. \& Exhi., Moscow, Russia, 28-30 Oct.

Hajibeygi, H., Karvounis, D. and Jenny, P. (2011) “A Hierarchical Fracture Model for the Iterative Multiscale Finite Volume Method” Journal of Computational Physics, vol.230, pp8729-8743.

Ibrahim, M. (2013) “Development of New Well Index Equation for Fracture Wells" SPE 164017 presented at the SPE Middle East Unconventional Gas Conf. and Exhi., Muscat, Oman, 28-30 Jan.

Lefevre, D., Pellissier, G. and Sabathier, J.C. (1993) “A New Reservoir Simulation System for a Better Reservoir Management”, SPE 25604 presented at the Middle East Oil Show, Bahrain, 3-6 April.

Li, L. and Lee, S.H. (2008) "Efficient Field-scale Simulation of Black Oil in a Naturally Fractured Reservoir Through Discrete Fracture Networks and Homogenized Media”, SPEREE, vol.11, No.4, pp750-758.

Mascarenhas, O. and Durlofsky, L.J., (2000) "Coarse scale simulation of horizontal wells in heterogeneous reservoirs", J. Petrol. Sci. Eng. 25, 135-147. 
Medeiros, F., Ozkan, E. and Kazemi, H. (2007) "Productivity and Drainage Area of Fractured Horizontal Wells in Tight Gas Reservoirs", SPE 108110 presented at the 2007 Rocky Mountain Oil \& Gas Tech. Sym., Denver, CO, USA, 16-18 April.

Moinfar, A., Varavei, A., Sepehrnoori, K. and Russel, T.J. (2013) « Development of a Coupled Dual Continuum and Discrete Fracture Model for the Simulation of Unconventional Reservoirs", Paper SPE 163647 presented at the SPE Reservoir Simulation Symposium, The Woodlands, TX, 18-20 Feb.

Nedelec, J.C. (2001) “Acoustic and Electromagnetic Equations: Integral Representations for Harmonic Problems” Applied Mathematical Sciences, vol. 144, Springer.

Norbeck, J., Huang, H., Podgorney, R. and Horne, R. (2014) “An Integrated Discrete Fracture Model for Description of Dynamic Behavior in Fractured Reservoirs" Thirty-Ninth Workshop on Geothermal Reservoir Engineering Stanford University, Stanford, CA, February 24-26.Peaceman, D.W. (1978) "Interpretation of Wellblock Pressures in Numerical Reservoir Simulation," SPEJ June pp183-194; Trans., AIME, 253.

Peaceman, D.W. (1983) "Interpretation of Wellblock Pressures in Numerical Reservoir Simulation With Nonsquare Gridblocks and Anisotropic Permeability", SPEJ, June, pp531

Peaceman, D.W. (1993) "Representation of a Horizontal Well in Numerical Reservoir Simulation," SPE Adv. Technology Series, Vol 1, No 1, pp7-16.

Sadrpanah, H., Charles, T. and Fulton, J. (2006) "Explicit Simulation of Multiple Hydraulic Fractures in Horizontal Wells", SPE 99575 presented at the SPE Europec/EAGE Annual Conf. and Exhi., Vienna, Austria, 12-15 June. 
Wu, Y.S. (2002) "Numerical Simulation of Single-Phase and Multiphase Non-Darcy Flow in Porous and Fractured Reservoirs," Transport in Porous Media, Vol. 49, No. 2, 209-240.

Wu, Y.S., Li, J., Ding, D.Y., Wang, C. and Di, Y. (2013) “A Generalized Framework Model for Simulation of Gas Production in Unconventional Gas Reservoirs", SPE 163609, presented at the SPE Reservoir Simulation Symposium, The Woodlands, TX, 18-20 Feb.

Zhou, Y. and King, M.J. (2011) "Improved Upscaling for Flow Simulation of Tight Gas Reservoir Models”, SPE 147355 presented at the SPE ATC\&E, Denver, CO, USA, 30 Oct. - 2 Nov.

\section{Appendix:}

Using boundary integral method and potential theory (Nedelec, 2001), the differential equation Eq. (8) can be written with an integral representation (Figure 2):

$$
P(x)=-\frac{1}{2 \pi} \int_{\Gamma_{f}} \varphi(y) \ln (|x-y|) d \sigma_{y}
$$

where $\varphi=\left.\frac{\partial p}{\partial n}\right|_{\Gamma^{-}}-\left.\frac{\partial p}{\partial n}\right|_{\Gamma^{+}}$is the single-layer potential defined on fracture boundary $\Gamma_{f}$ with $\Gamma^{+}$and $\Gamma^{-}$the exterior and interior boundary of the fracture. The relation between the single-layer potential $\varphi$, which is defined on the fracture boundary, and the fracture pressure $P_{f}$ on the fracture boundary, is given by the following equation:

$$
P_{f}(x)=-\frac{1}{2 \pi} \int_{\Gamma_{f}} \varphi(y) \ln (|x-y|) d \sigma_{y} \quad \forall x \in \Gamma_{f}
$$

Besides, the fracture inflow $Q_{f}(x)=\frac{\partial P}{\partial n}(x)$ from the reservoir to the fracture is given by:

$$
Q_{f}(x)=-\frac{\varphi(x)}{2}-\frac{1}{2 \pi} \int_{\Gamma_{f}} \varphi(y) \frac{\partial}{\partial n_{x}}(\ln (|x-y|)) d \sigma_{y} \quad \forall \mathrm{x} \in \Gamma_{f}
$$


According to the fracture boundary condition, the integral equation Eq.(A2) or Eq.(3) will be solved to get the potential $\varphi$. This kind of approach is sometimes called as semi-analytical method. For example, for an infinite conductivity fracture, the potential $\varphi$ can be obtained by solving the following equation:

$$
C=-\frac{1}{2 \pi} \int_{\Gamma_{f}} \varphi(y) \ln (|x-y|) d \sigma_{y} \quad \forall \mathrm{x} \in \Gamma_{f}
$$

Once the potential $\varphi$ is known, we can get the pressure distribution with Eq.(A1), the fracture pressure $P_{f}(x)$ with Eq.(A2) and the fracture inflow $Q_{f}(x)$ with Eq.(A3).

In this work, we are particularly interested in the constant potential condition, where an analytical solution can be obtained. Considering the origin of the coordinate is at the center of the fracture, and $x_{1}$ direction is oriented along the fracture length as shown in Figure 2. Let $\varphi \equiv C$ a constant, by neglecting the contribution from the two small rectangular surfaces of width $w$ at the fracture extremities, the pressure field at a point $x$ with Eq.(A1) is approximated by:

$$
P(x) \approx-\frac{C}{2 \pi}\left(\int_{-X_{f}}^{X_{f}} \ln \left(\sqrt{\left(x_{1}-y_{1}\right)^{2}+\left(x_{2}+\frac{w}{2}\right)^{2}}\right) d y_{1}+\int_{-X_{f}}^{X_{f}} \ln \left(\sqrt{\left(x_{1}-y_{1}\right)^{2}+\left(x_{2}-\frac{w}{2}\right)^{2}}\right) d y_{1}\right)
$$

where $X_{f}$ is the fracture half length, and $w$ is the fracture width. The fracture boundary is composed of two parts: first term corresponds to the fracture boundary below $\mathrm{x}$-axis $(y=-w / 2)$ and the second term corresponds to the fracture boundary above $\mathrm{x}$-axis $(y=w / 2)$. By neglecting the fracture width $w$ (for $x$ not too close to the fracture), we get

$$
\begin{aligned}
P(x) \approx-\frac{C}{2 \pi} \int_{-X_{f}}^{X_{f}} \ln \left(\left(x_{1}-y_{1}\right)^{2}+x_{2}^{2}\right) d y_{1} \\
=-\frac{C}{2 \pi}\left(\left(X_{f}-x_{1}\right) \ln \left(\left(X_{f}-x_{1}\right)^{2}+x_{2}^{2}\right)+\left(X_{f}+x_{1}\right) \ln \left(\left(X_{f}+x_{1}\right)^{2}+x_{2}^{2}\right)\right. \\
\left.\quad+2 x_{2}\left(\operatorname{arctg}\left(\frac{X_{f}-x_{1}}{x_{2}}\right)+\operatorname{arctg}\left(\frac{X_{f}+x_{1}}{x_{2}}\right)\right)-4 X_{f}\right)
\end{aligned}
$$


The pressure on the fracture boundary $P_{f}(x)$ with Eq.(A2) is approximated by (neglecting always the contribution from the two fracture extremities):

$$
\begin{aligned}
P_{f}(x) \approx-\frac{C}{2 \pi}\left(\int_{-X_{f}}^{X_{f}} \ln \left(\sqrt{\left(x_{1}-y_{1}\right)^{2}}\right) d y_{1}+\int_{-X_{f}}^{X_{f}} \ln \left(\sqrt{\left(x_{1}-y_{1}\right)^{2}+w^{2}}\right) d y_{1}\right) \\
=-\frac{C}{2 \pi}\left(\left(X_{f}-x_{1}\right) \ln \left(X_{f}-x_{1}\right)+\left(X_{f}+x_{1}\right) \ln \left(X_{f}+x_{1}\right)-2 X_{f}\right. \\
+\frac{1}{2}\left(X_{f}-x_{1}\right) \ln \left(\left(X_{f}-x_{1}\right)^{2}+w^{2}\right)+\frac{1}{2}\left(X_{f}+x_{1}\right) \ln \left(\left(X_{f}+x_{1}\right)^{2}+w^{2}\right) \\
\left.+w\left(\operatorname{arctg}\left(\frac{X_{f}-x_{1}}{w}\right)+\operatorname{arctg}\left(\frac{X_{f}+x_{1}}{w}\right)\right)-2 X_{f}\right)
\end{aligned}
$$

If the fracture width $w$ is neglected, the calculation can be simplified by:

$$
P_{f}(x) \approx-\frac{C}{\pi}\left(\left(X_{f}-x_{1}\right) \ln \left(X_{f}-x_{1}\right)+\left(X_{f}+x_{1}\right) \ln \left(X_{f}+x_{1}\right)-2 X_{f}\right)
$$

Moreover, the fracture inflow $Q_{f}(x)$ with Eq.(A3) is approximated by:

$$
\begin{aligned}
Q_{f}(x) & \approx-\frac{C}{2}-\frac{C}{2 \pi}\left(\int_{-X_{f}}^{X_{f}} \frac{x_{2}+w / 2}{\left(x_{1}-y_{1}\right)^{2}+\left(x_{2}+w / 2\right)^{2}} d y_{1}-\int_{-X_{f}}^{X_{f}} \frac{x_{2}-w / 2}{\left(x_{1}-y_{1}\right)^{2}+\left(x_{2}-w / 2\right)^{2}} d y_{1}\right) \\
& =-\frac{C}{2}-\frac{C}{2 \pi}\left(\int_{-X_{f}}^{X_{f}} \frac{w}{\left(x_{1}-y_{1}\right)^{2}+w^{2}} d y_{1}\right) \\
& =-\frac{C}{2}-\frac{C}{2 \pi}\left(\operatorname{arctg}\left(\frac{X_{f}-x_{1}}{w}\right)+\operatorname{arctg}\left(\frac{X_{f}+x_{1}}{w}\right)\right) \\
& \approx-\mathrm{C}
\end{aligned}
$$

The last step is obtained by the fact that $w$ is small. This equation Eq.(A7) also shows that the constant potential is equivalent to the uniform flux condition for the fractures. With Eqs.(A5) (A7), we can determine near-fracture transmissibility with Eq.(5) and FCI with Eq.(11) for the fractured well modeling. 
Table 1 - Time steps for data updating in the coupled modeling

\begin{tabular}{|c|c|c|}
\hline Coarse grid full-field model & \multicolumn{2}{|c|}{ Time steps for the data exchange (day) } \\
\hline Time (day) & well W1 & well W2 \\
\hline $0-1$ & No coupling & No coupling \\
\hline $1-21$ & 1 & No coupling \\
\hline $21-31$ & 5 & 1 \\
\hline $31-51$ & 5 & 1 \\
\hline $51-61$ & 10 & No coupling \\
\hline $61-201$ & 10 & No coupling \\
\hline $201-800$ & No coupling & \\
\hline
\end{tabular}




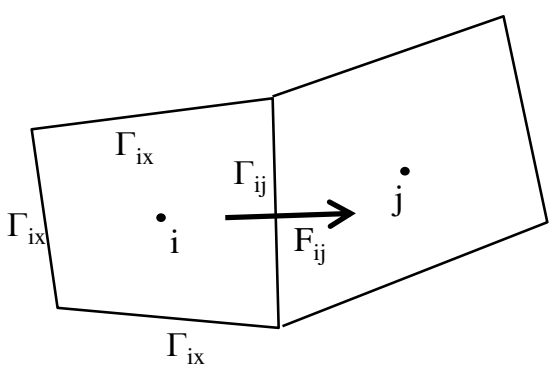

Figure 1-Flux approximation in comtrol-volume method

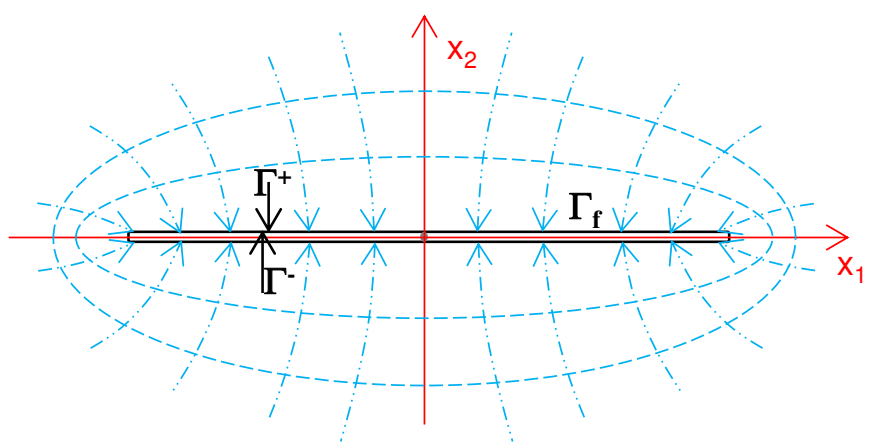

Figure 2-Modeling of steady-state flow towards the fracture

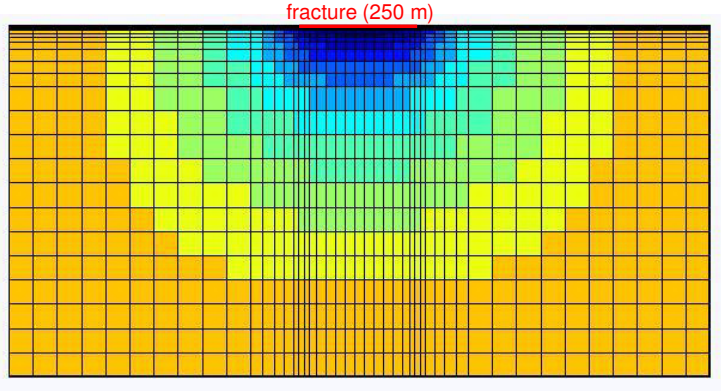

(a)

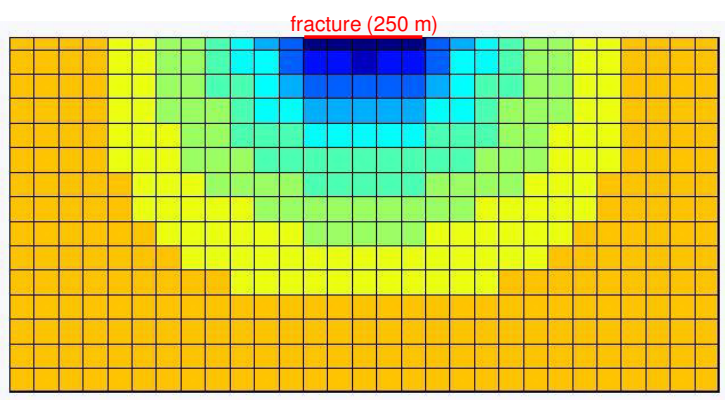

(b)

Figure 3-Discretization of a single fractured horizontal well (pressure distribution at 800 days with $C_{f}=100$ in the conventional reservoir):

(a) fine grid system; (b) coarse grid system 


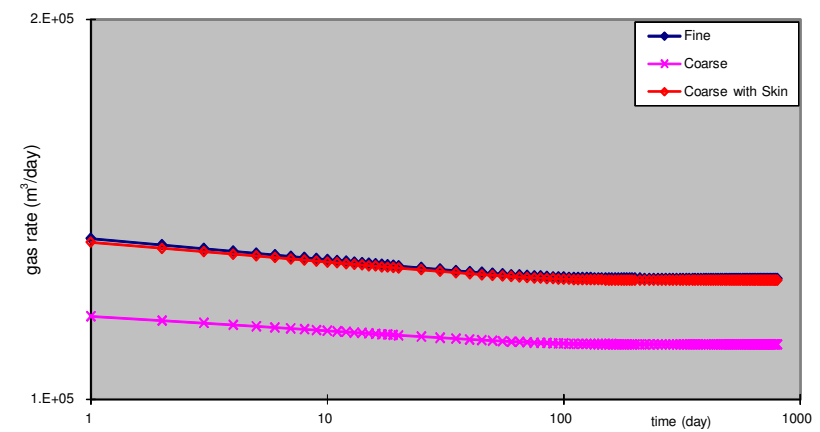

(a)

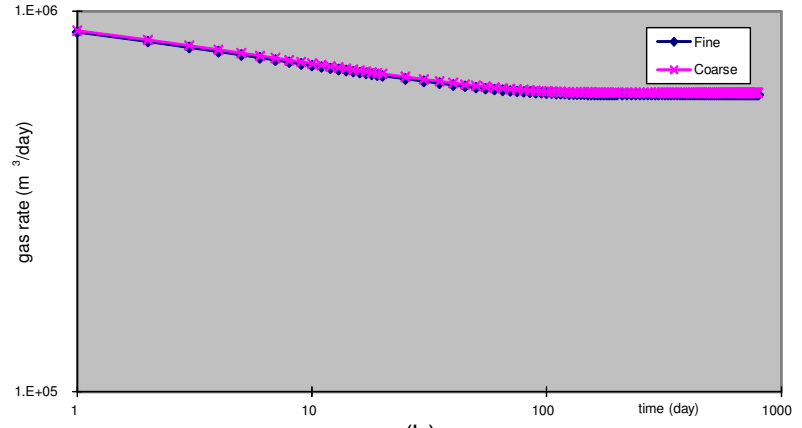

(b)

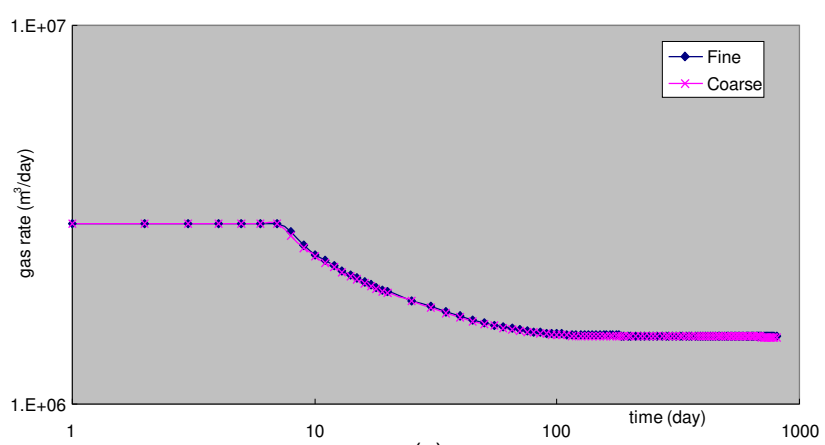

(c)

Figure 4 - Comparison between coarse grid and fine grid simulations in a conventional reservoir: (a) $\mathrm{C}_{\mathrm{f}}=0.1 ;$ (b) $\mathrm{C}_{\mathrm{f}}=1 ;$ (c) $\mathrm{C}_{\mathrm{f}}=100$

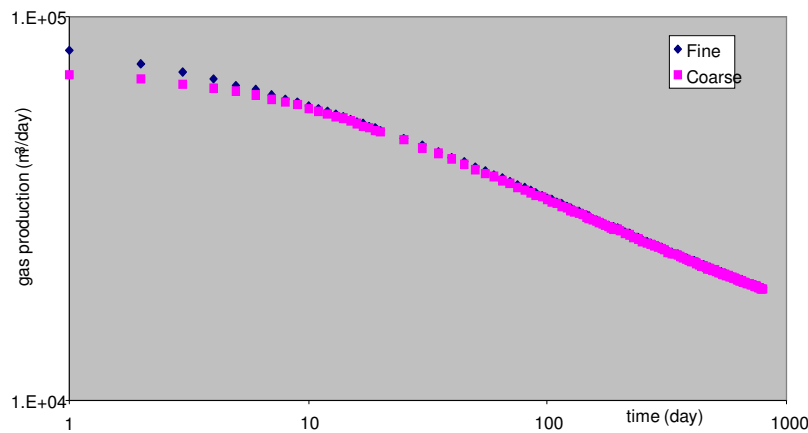

(a)

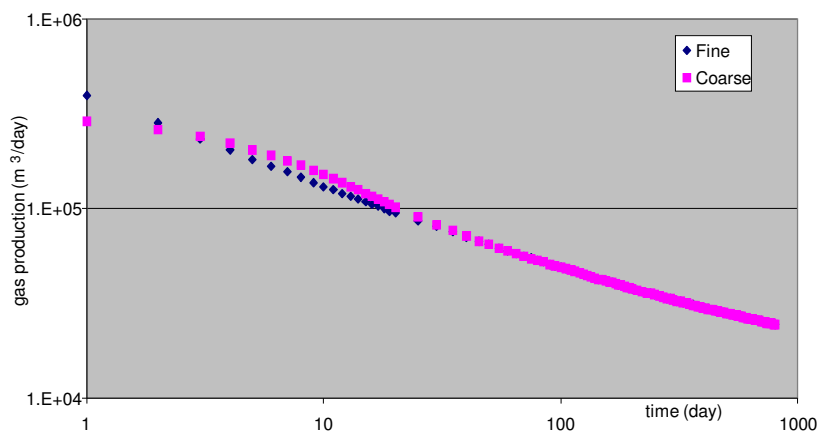

(b)

Figure 5-Comparison between coarse grid and fine grid simulations in a tight reservoir:

(a) $\mathrm{C}_{\mathrm{f}}=1$; (b) $\mathrm{C}_{\mathrm{f}}=10$ 
fracture $(250 \mathrm{~m})$

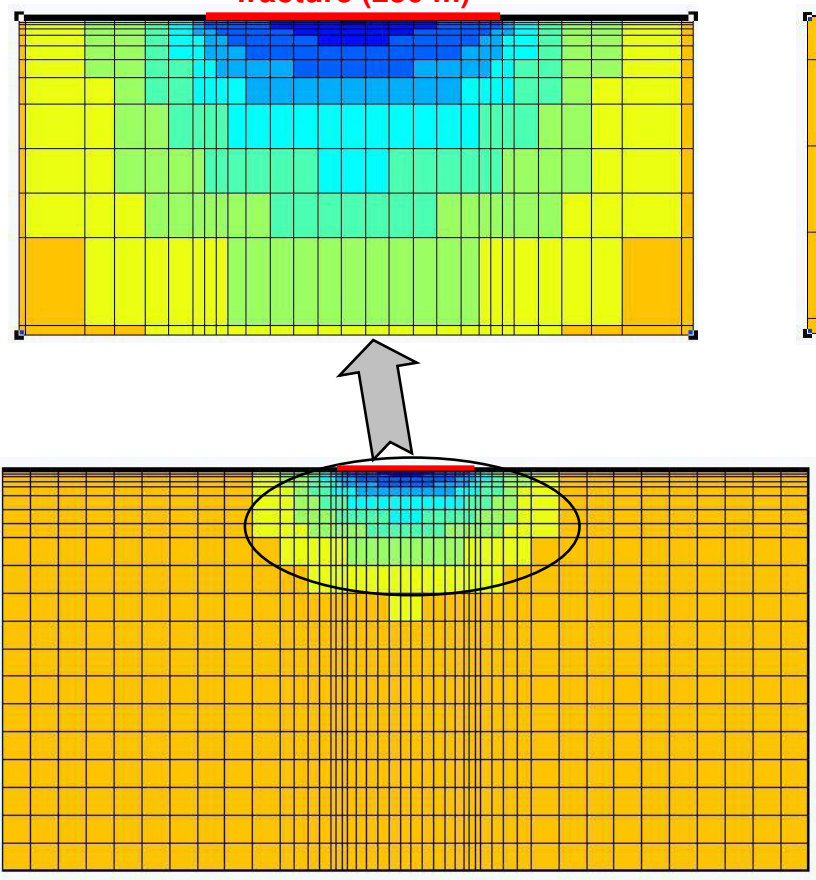

(a)

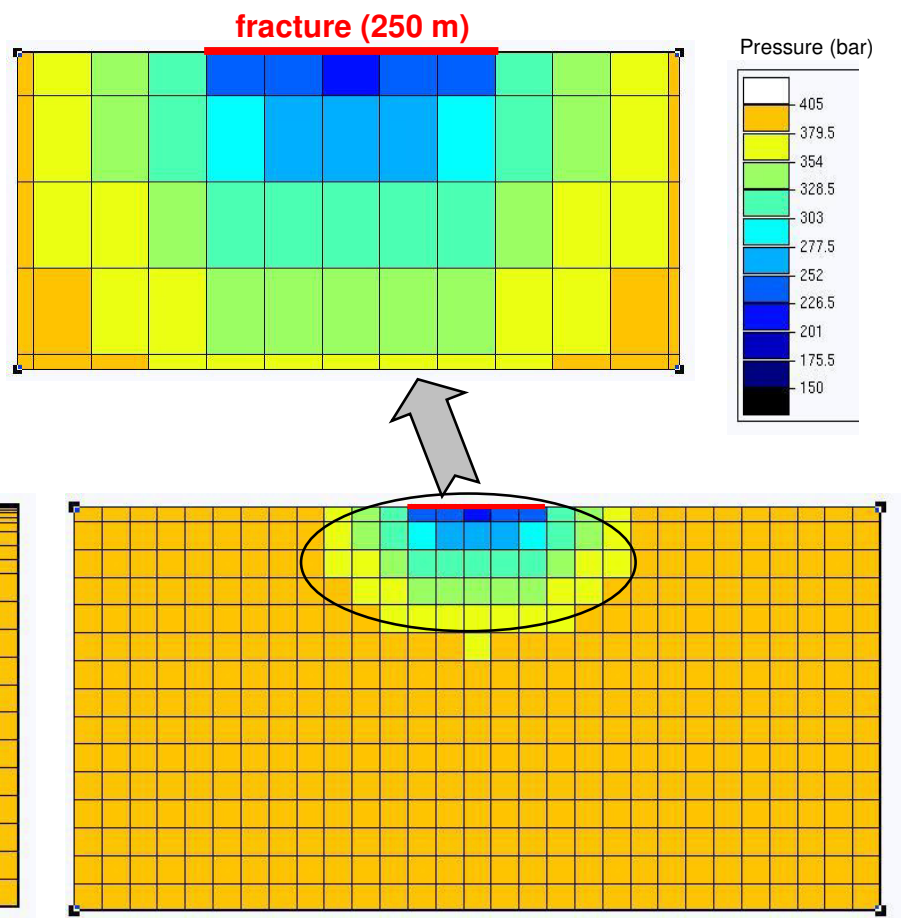

(b)

Figure 6 - Pressure distribution with coarse grid and fine grid simulations in a tight reservoir: (a) fine grid simulation; (b) coarse grid simulation

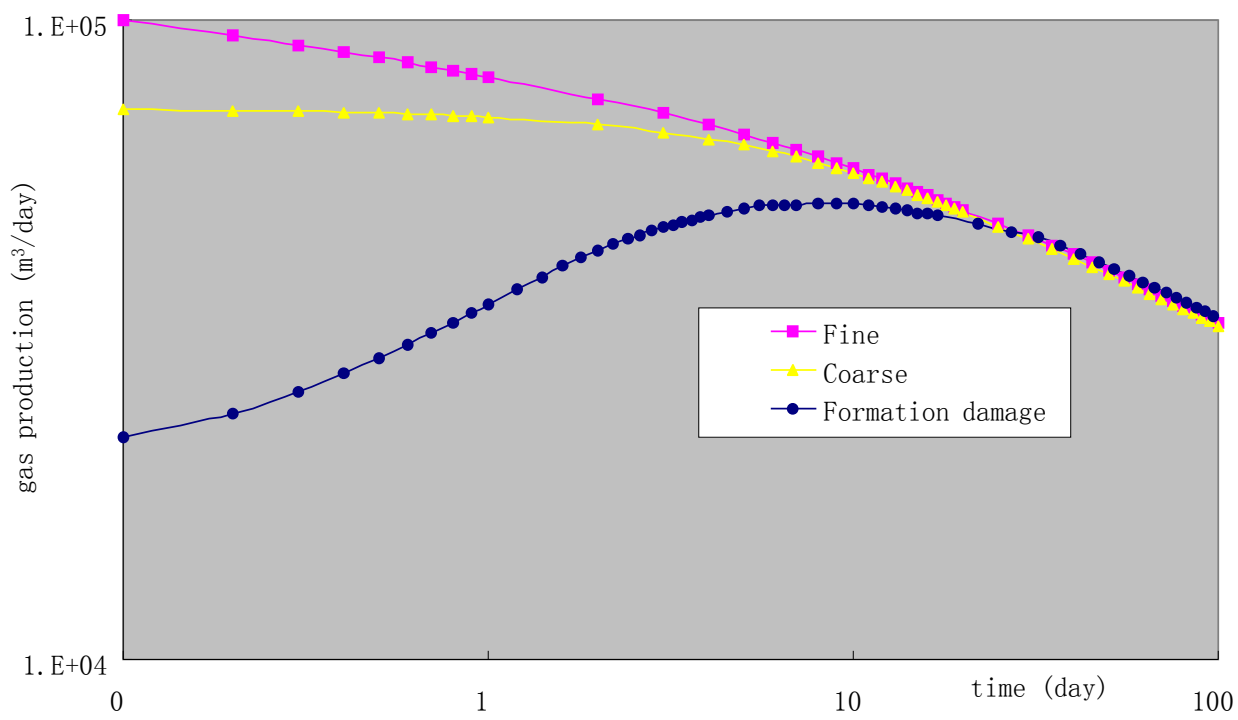

Figure 7-Transient effect with considering fracturing fluid induced formation damage 


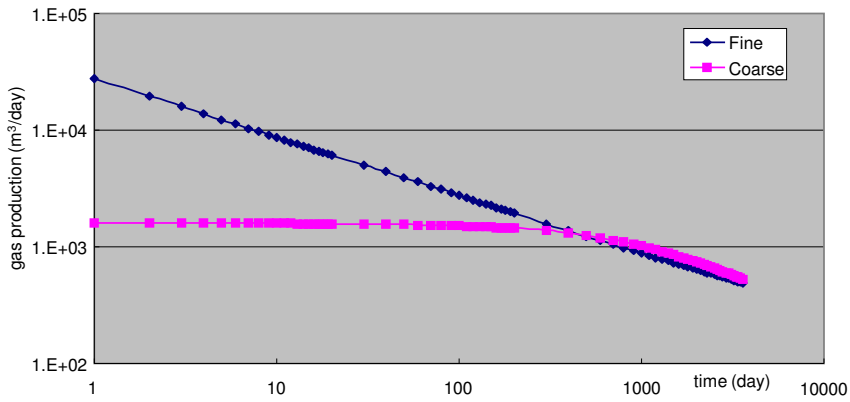

(a)

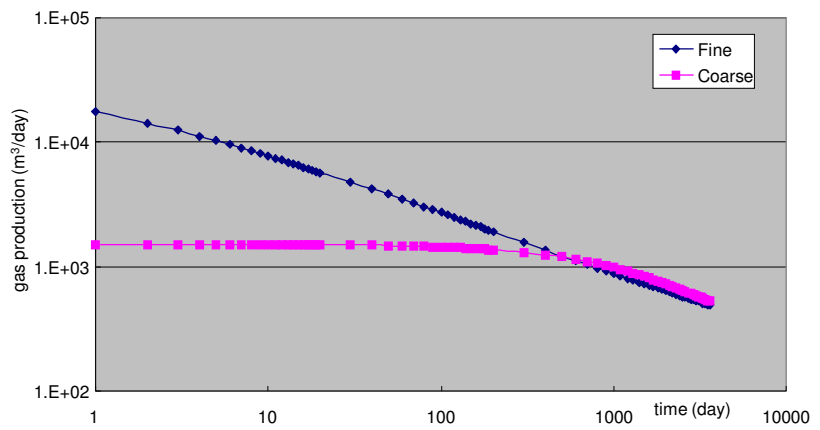

(b)

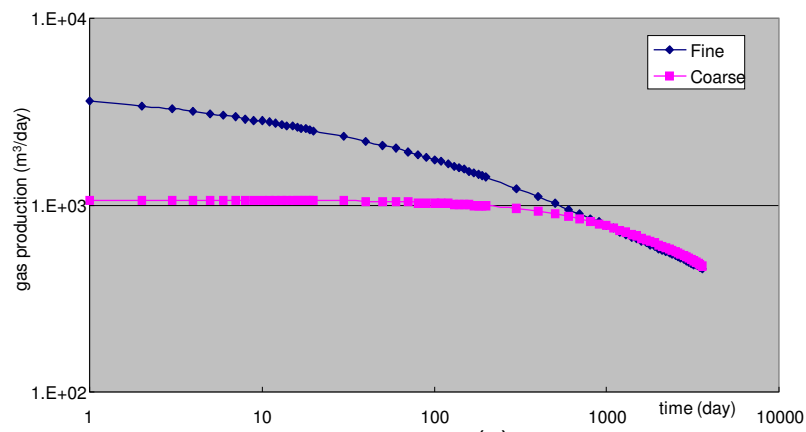

(c)

Figure 8 - Comparison between coarse grid and fine grid simulations in a shale gas reservoir:

(a) $\mathrm{C}_{\mathrm{f}}=2000 ;$ (b) $\mathrm{C}_{\mathrm{f}}=160 ;$ (c) $\mathrm{C}_{\mathrm{f}}=16$

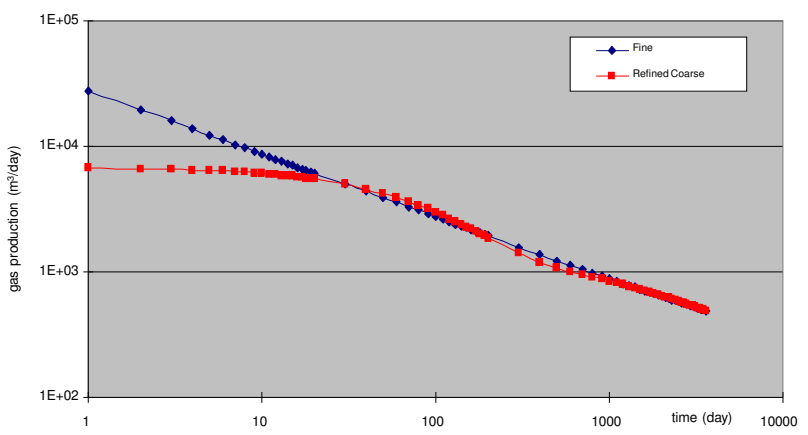

(a)

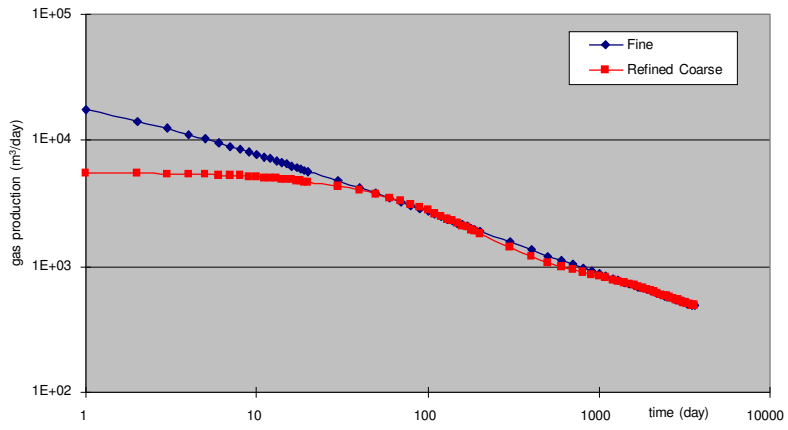

(b)

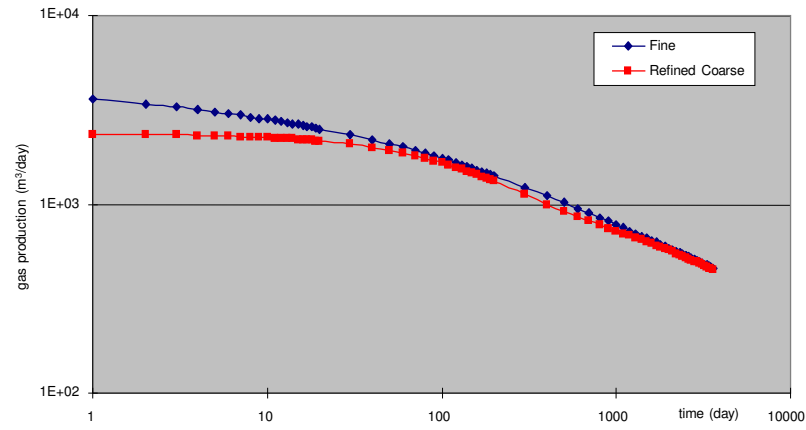

(c)

Figure 9 - A slight refinement of fracture blocks in coarse grid simulations in the shale gas reservoir: (a) $\mathrm{C}_{\mathrm{f}}=2000 ;$ (b) $\mathrm{C}_{\mathrm{f}}=160 ;$; (c) $\mathrm{C}_{\mathrm{f}}=16$ 


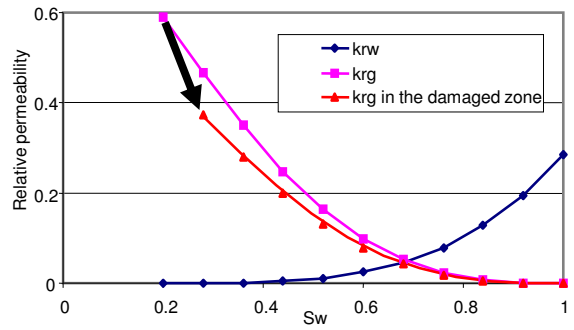

(a)

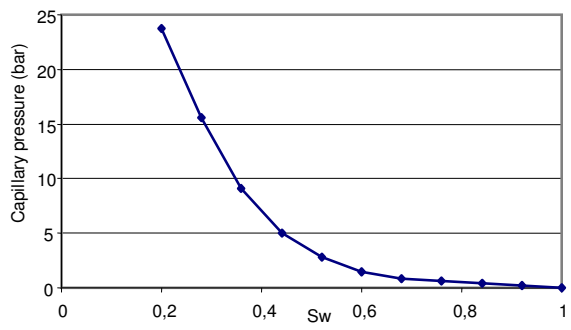

(b)

Figure 10-Relative permeability and capillary pressure: (a) hysteresis of gas relative permeability; (b) capillary pressure

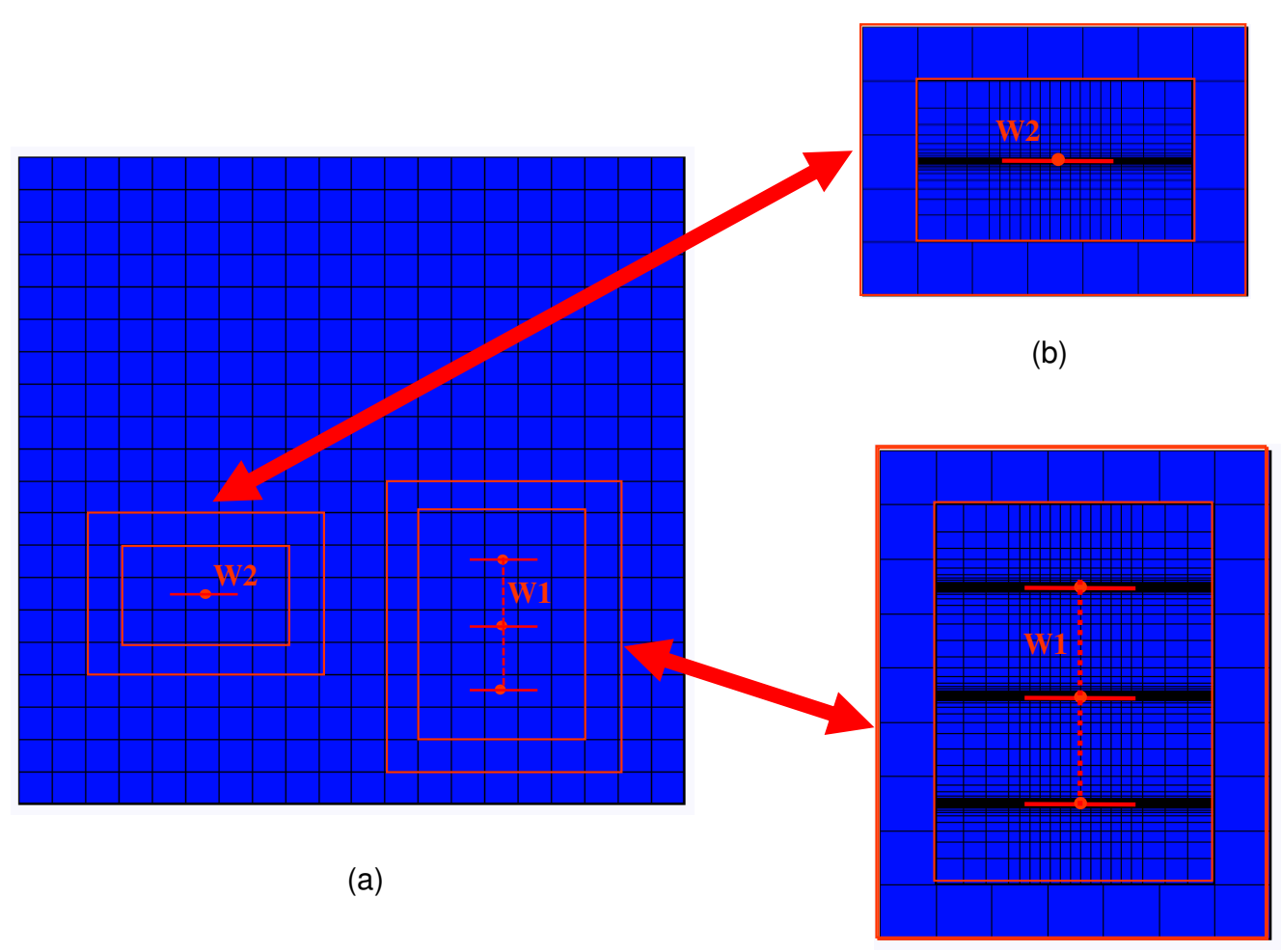

(c)

Figure 11 - Coupled modeling of a two-well system:

(a) full-field coarse grid; (b) near-fracture model for well W2; (c) near-fracture model for well W1 


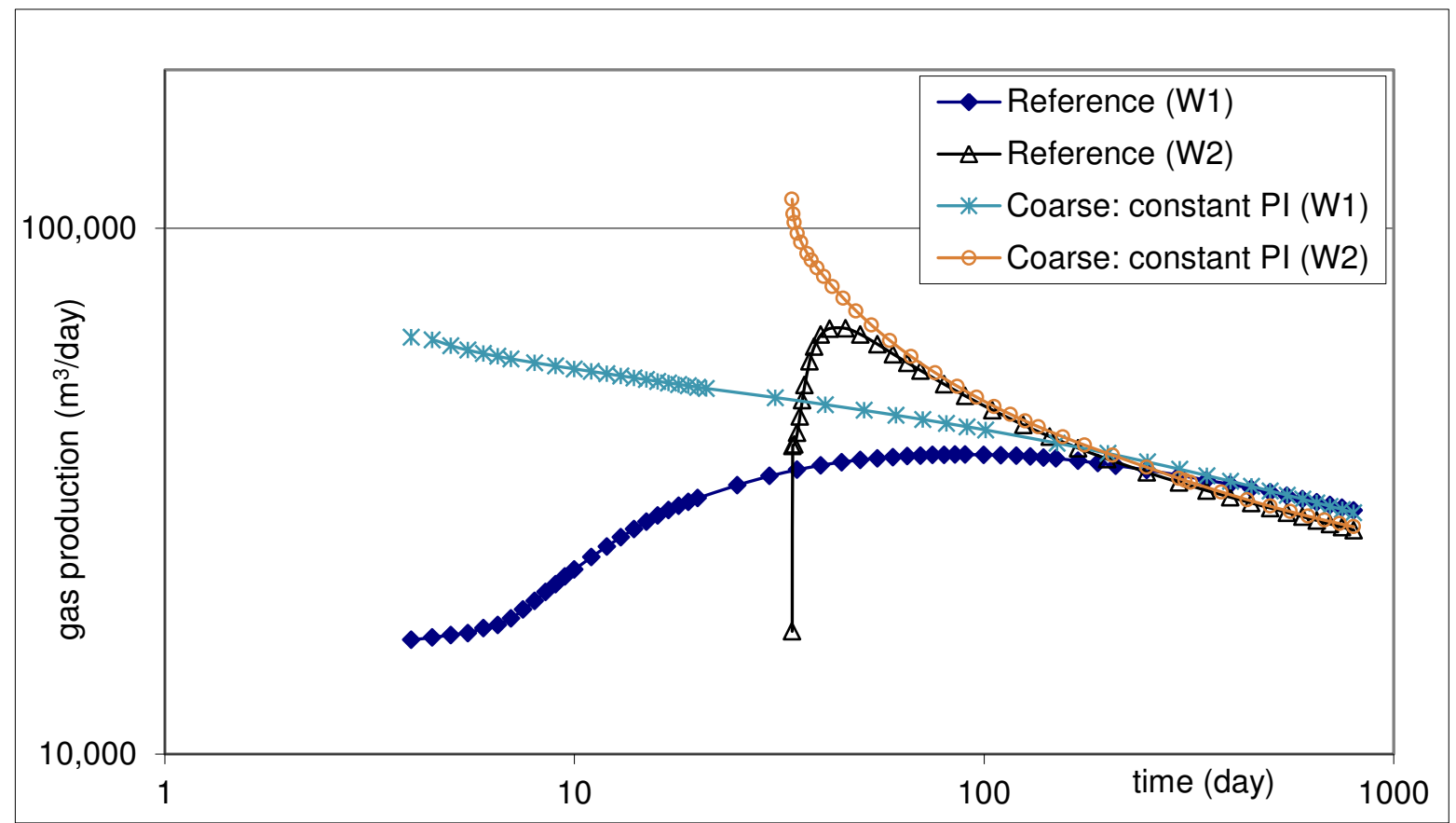

Figure 12 - Coarse grid simulation with constant PI

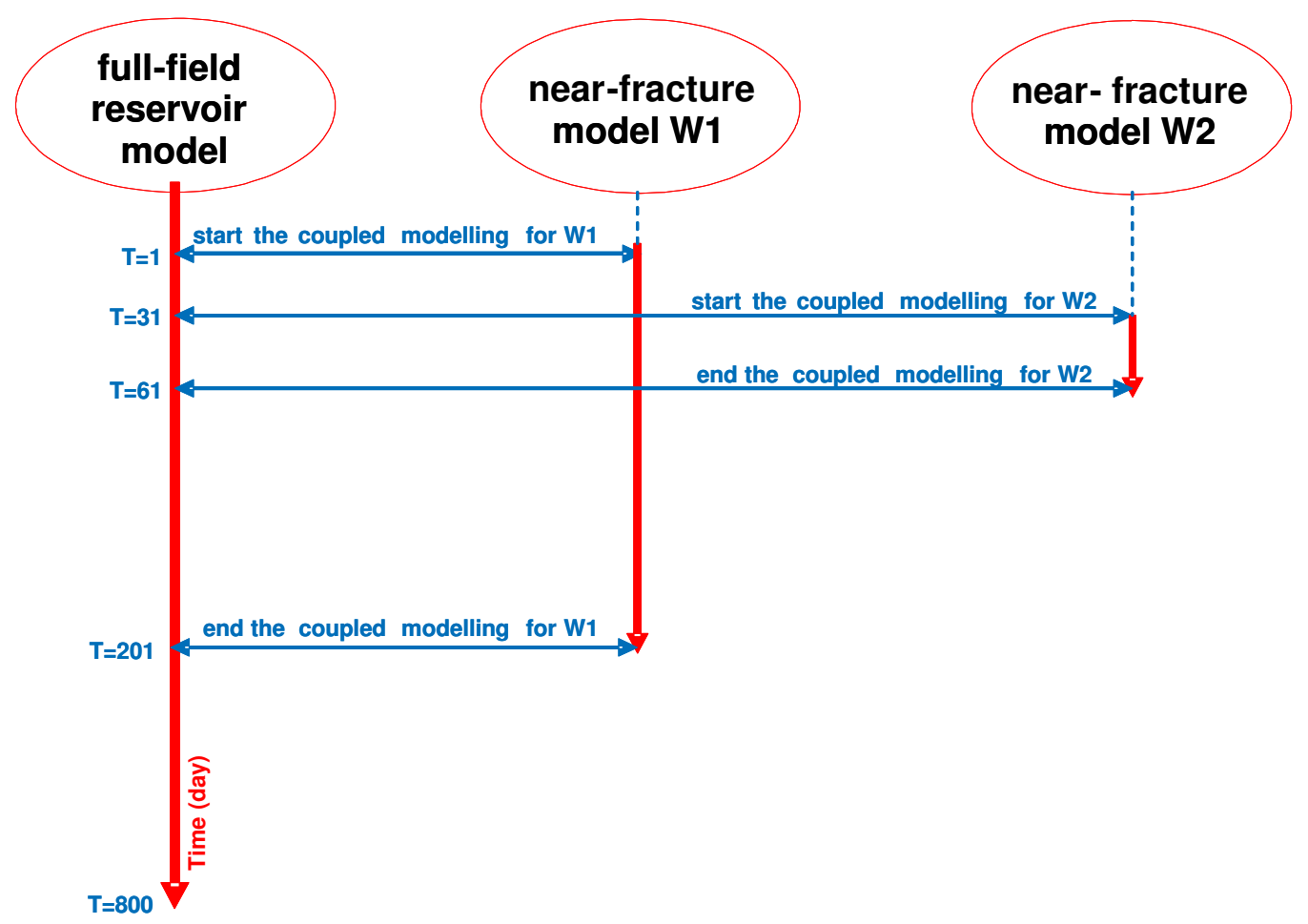

Figure 13 - Time period for the coupled modeling 


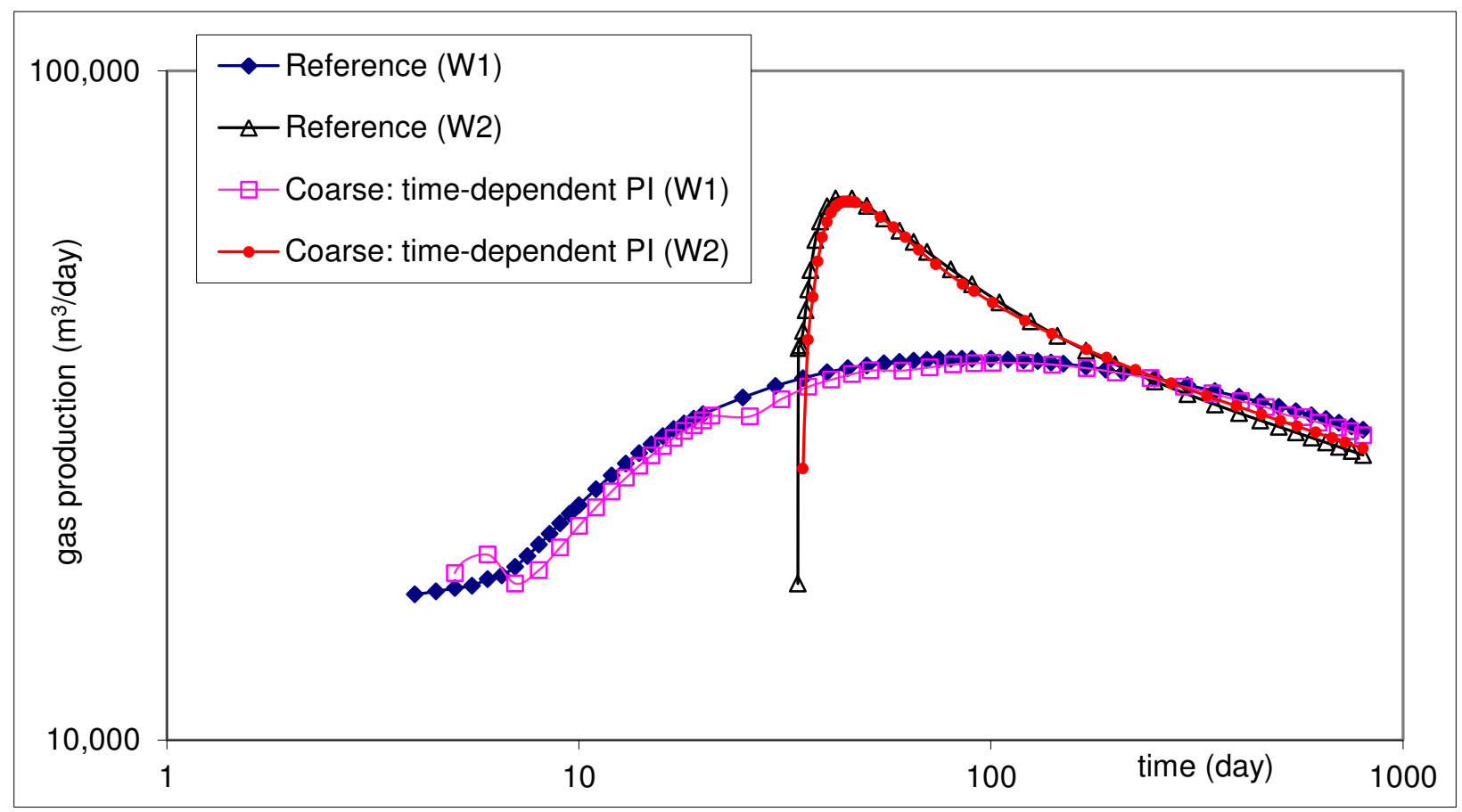

Figure 14 - Coarse grid simulation with time-dependent PI 